\title{
As bibliotecas e o percurso histórico de abertura da ciência: revendo um roteiro de colaboração
}

\author{
Libraries and the historical course of open science: reviewing a collaboration roadmap
}

\author{
Jorge Revez \\ Universidade de Lisboa. Faculdade de Letras. Programa em Ciências da \\ Documentação e Informação e Centro de Estudos Clássicos, Portugal \\ jrevez@campus.ul.pt
}

\section{Resumo:}

A ciência é marcada atualmente por movimentos de tensão e rutura, cada vez mais acentuados e em ciclos de curta duração. Acesso Aberto, Dados Abertos, Ciência Aberta, entre outros, são conceitos operatórios fundamentais na relação das bibliotecas com a produção e a disseminação da ciência. Este trabalho é uma revisão da literatura, que procura acompanhar o roteiro histórico de colaboração entre as bibliotecas e a abertura da ciência. Almeja-se traçar o cenário que marca hoje a ciência - do movimento do Acesso Aberto à Ciência Aberta -, na tentativa de compreender em que medida esse panorama influencia o papel das bibliotecas na investigação científica. O objetivo é fornecer uma imagem geral da Ciência Aberta, focando particularmente as implicações teóricas que esta paisagem acarreta para as bibliotecas. A principal questão é perceber, por um lado, o que significa o Acesso Aberto e a Ciência Aberta para as bibliotecas, e como estão a comportar-se perante estas dinâmicas; por outro lado, como é que os investigadores encaram o papel das bibliotecas neste amplo e novo panorama científico. Estas questões serão observadas em uma estrutura de revisão dividida em três partes: origens do Acesso Aberto, a emergência da Ciência Aberta e o papel das bibliotecas na abertura da ciência. Conclui-se que as bibliotecas participaram desde o início no processo de abertura da ciência e continuam hoje a pugnar pelo desempenho de um papel relevante neste processo social e cultural.

Palavras-Chave: Acesso Aberto, Ciência Aberta, Bibliotecas, Produção e Disseminação da Ciência.

\section{AbStract:}

Science is currently marked by movements of tension and rupture, increasingly sharp and in cycles of short duration. Open Access, Open Data, Open Science, among others, are fundamental operative concepts in the relationship between libraries and science production and dissemination. This work is a literature review, that seeks to follow the historical roadmap of collaboration between libraries and the opening of science. Outlining the scenario that marks science today - from the Open Access to Open Science movement - the intention is to understand to what extent this landscape influences the role of libraries in scientific research. The objective is to provide a general picture of Open Science, focusing on the theoretical implications that this landscape entails for libraries. The main issue is to understand, on the one hand, what Open Access and Open Science mean for libraries and how they are behaving in the face of these dynamics; on the other hand, how researchers view the role of libraries in this broad and new scientific landscape. These issues will be observed in a review structure divided into three parts: Open Access origins, the emergence of Open Science, and the role of libraries in opening science. It is concluded that libraries participated from the beginning in the process of opening science and continue to strive today to play a relevant role in this social and cultural process.

KEYwords: Open Access, Open Science, Libraries, Science Production and Dissemination.

\section{INTRODUÇÃO}

O percurso histórico de abertura da ciência é um processo longo e em desenvolvimento, não sendo possível vaticinar as suas etapas futuras ou o seu epílogo. $\mathrm{Na}$ sua essência, trata-se de um processo cultural e civilizacional, que implica um dos mais fortes dispositivos da modernidade: a ciência, isto é, o conhecimento científico e a sua dimensão comunicacional, na forma que emergiu a partir da Revolução Científica do séc. XVII. 
Nesta dinâmica de abertura, de uma forma lata, desenha-se um panorama multifatorial onde interagem elementos e preocupações de índole académica, económica, comercial, política e social, que colocam em questão a própria sustentabilidade do sistema de produção e disseminação da ciência. Neste contexto, é possível afirmar que as bibliotecas têm tido a intenção de desempenhar, ao longo do tempo, um papel-chave na abertura da ciência, ocupando, em diferentes momentos, posições de destaque.

Pretende-se com este trabalho efetuar a revisão desse roteiro de colaboração entre as bibliotecas e a abertura da ciência. Almeja-se traçar o cenário que marca hoje a ciência - do movimento do Acesso Aberto (AA) à Ciência Aberta (CA) -, procurando compreender em que medida esse panorama influencia o papel das bibliotecas na investigação científica. O objetivo é fornecer uma imagem geral da CA, focando particularmente as implicações teóricas que esta paisagem acarreta para as bibliotecas.

A ciência é marcada atualmente por movimentos de tensão e rutura, cada vez mais acentuados e em ciclos de curta duração. AA, Dados Abertos, CA, entre outros, são conceitos operatórios fundamentais na relação das bibliotecas com os investigadores. A principal questão teórica é perceber, por um lado, o que significa o AA e a CA para as bibliotecas, e como estão a comportar-se perante estas dinâmicas; por outro lado, como é que os investigadores encaram o papel das bibliotecas neste amplo e novo panorama científico.

Estas questões serão observadas em uma estrutura de revisão dividida em três partes: origens do Acesso Aberto, a emergência da Ciência Aberta e o papel das bibliotecas na abertura da ciência.

\section{Origens do Acesso Aberto}

Uma abordagem exaustiva às origens do AA exigiria um estudo de natureza genealógica. Moore reconhece que o desenvolvimento do AA revela linhagens diferentes, desde a formalização de culturas de intercâmbio de preprints, pré-existentes através de repositórios temáticos e o posterior surgimento dos repositórios institucionais, até à ideia de cultura livre e aos movimentos de software de código aberto. O AA tem, por isso, uma genealogia complexa que não pode ser retratada como um movimento coerente ou homogéneo. Não só existem linhagens separadas (abertura do processo investigativo, por um lado, acesso à investigação produzida, por outro), como dentro destas linhagens existem numerosas motivações e entendimentos do termo (Moore, 2017).

A definição e o cunho fornecidos na Declaração da Budapest Open Access Initiative, conhecida também pelo acrónimo BOAI, de 14-02-2002, são ainda hoje uma referência:

Por “acesso aberto" a esta literatura, nos referimos à sua disponibilidade gratuita na internet, permitindo a qualquer usuário a ler, baixar, copiar, distribuir, imprimir, buscar ou usar desta literatura com qualquer propósito legal, sem nenhuma barreira financeira, legal ou técnica que não o simples acesso à internet. A única limitação quanto à reprodução e distribuição, e o único papel do copyright neste domínio sendo o controle por parte dos autores sobre a integridade de seu trabalho e o direito de ser propriamente reconhecido e citado. (BOAI, 2002)

A Declaração de Budapeste, considerada o ponto de partida do movimento do AA enquanto dinâmica pública e de cariz internacional, começava por reconhecer que a velha tradição de os cientistas publicarem, de forma gratuita, os resultados da investigação em revistas científicas se combinava agora com uma nova tecnologia, a Internet, de forma a permitir a emergência de um bem público sem precedentes: a distribuição eletrónica mundial da literatura científica, em acesso livre e sem restrições. Eram então propostas duas vias para atingir este fim: o auto-arquivo em repositórios abertos - mais tarde chamada via verde - e a publicação em revistas em acesso aberto - mais tarde chamada via dourada.

Dez anos depois (2012) foram publicados em Budapeste um balanço e um conjunto de recomendações, a partir do trabalho já realizado desde 2002, relativamente ao que se designou como "uma campanha mundial em prol do acesso aberto a todas as novas publicações científicas com revisão por pares”. Neste documento, assinalava-se que a BOAI não havia inventado o $\mathrm{AA}$, mas foi 
a primeira iniciativa a usar o termo 'open access' para este propósito, a primeira a articular uma definição pública, a primeira a propor estratégias complementares para atingir o OA [Open Access], a primeira a generalizar o apelo ao OA a todas as disciplinas e países, e a primeira a ser acompanhada por financiamento significativo (BOAI, 2017) (http://www.budapesto penaccessinitiative.org/boai-10-translations/portuguese).

A única vez que a palavra bibliotecas aparece mencionada nas recomendações referidas é no apelo a que a campanha mundial pelo AA trabalhasse

em maior proximidade com a campanha mundial pelo OA aos livros, teses e dissertações, dados científicos, dados governamentais, recursos educativos e código-fonte. Devemos coordenar com esforços afins menos diretamente relacionados com o acesso aos resultados da investigação, como a reforma dos direitos de autor, obras órfã̃s, preservação digital, digitalização de literatura impressa, decisão política baseada em evidências, a liberdade de expressão e a evolução de bibliotecas, publicação, revisão por pares e medias sociais. (BOAI, 2017)

Almejava-se, desta forma, o alargamento dos tipos de recursos de informação em acesso aberto, entre os quais os dados de investigação, e a interligação da campanha com um conjunto de ações correlacionadas, entre as quais se incluía o desenvolvimento das bibliotecas.

Independentemente desta menção específica às bibliotecas, a sua intervenção está implícita em muitos itens das recomendações. Bastaria referir o exemplo de várias recomendações destinadas às instituições do Ensino Superior que, na prática, são operacionalizadas pelas bibliotecas, como é o caso da gestão dos repositórios de acesso aberto, do apoio ao autoarquivo dos investigadores ou do depósito das teses e dissertações.

O documento apresentava ainda um conjunto de "verdades" sobre o AA, das quais se pode inferir que, na construção dessas "verdades", as bibliotecas têm uma quota-parte de responsabilidade, seja o benefício do AA para a investigação e para os investigadores, seja a amplificação do valor social da investigação, ou o aumento do retorno do investimento público na investigação, entre outros. Observando-se retrospetivamente a Declaração de Budapeste de 2002, o documento publicado dez anos depois revela que, teoricamente, neste momento consensualmente considerado seminal, as bibliotecas estavam totalmente implicadas no movimento do AA.

No mesmo sentido, Friend reconhece nestas raízes do AA a ação quer da comunidade bibliotecária, quer da comunidade académica. Embora as origens do AA sejam percebidas como preocupações dos bibliotecários sobre o aumento dos preços da literatura, os membros da comunidade académica foram os primeiros a disponibilizar gratuitamente os preprints na Internet. O autoarquivo começou em larga escala com o depósito de preprints oriundos da Física na base arXiv (lançado em 1991). Stevan Harnad teve a visão, logo em 1994, de que o autoarquivo poderia ser estendido à generalidade da literatura científica (Friend, 2006).

Borgman (2015) refere que o arXiv foi um gigante salto em frente no acesso aos resultados da investigação. A partir desta experiência é possível extrair três lições: (1) o arXiv emergiu da cultura de troca de preprints característica da Física, sendo assim criado sobre uma infraestrutura de conhecimento que já existia e que suportava esse "colégio invisível"; (2) o arXiv rompeu essa infraestrutura ao modificar as relações estabelecidas entre autores, editores, bibliotecas e leitores; (3) o sucesso do arXiv não se verificou noutras áreas do conhecimento, pelo menos não com o seu grau de implantação no terreno das práticas científicas.

Depois da Declaração de Budapeste de 2002, a campanha e a discussão mundial em torno do AA continuaram com diversos eventos e declarações a serem publicadas (Borges, 2006, pp. 92-95). As bibliotecas permaneceram omnipresentes e foram paulatinamente definindo o seu lugar, em termos políticos e em termos operacionais. Logo, em 2003, duas importantes declarações foram publicadas. A Declaração de Belém (Bethesda Statement on Open Access Publishing, 20-06-2003), focada na edição científica, incluiu uma secção dedicada às propostas apresentadas pelas bibliotecas, em que se destacava o apoio à edição em acesso aberto e a formação dos utilizadores para as vantagens das publicações em acesso aberto. No mesmo ano, a Declaração de Berlim (Berlin Declaration on Open Access to Knowledge in the Sciences and Humanities, 22-10-2003) 
mencionava as bibliotecas como um dos atores envolvidos na criação de uma base global de conhecimento científico e saber humano.

Peter Suber, um dos mais destacados ativistas do AA, propôs uma definição de AA que coordenasse as três declarações (Budapeste, Belém e Berlim). Indo além do acesso gratuito, este autor propunha que os utilizadores pudessem usufruir de permissão para qualquer uso académico da informação. Removiam-se também as barreiras de permissão, em complemento às barreiras de preços (Suber, 2004). Suber publicou também um livro essencial sobre o tema, onde definia AA da seguinte forma sintética: a literatura em acesso aberto é digital, está em linha, é gratuita e livre da maior parte das restrições de copyright e de licenciamento (Suber, 2012).

Em termos de associações de bibliotecas, a ACRL (Association of College and Research Libraries) publicou, também em 2003, os Principles and Strategies for the Reform of Scholarly Communication, sobre o sistema de comunicação da ciência, no qual se diagnosticavam diversos elementos da crise do sistema e se advogava uma reforma. Às bibliotecas era solicitado um compromisso com a reforma do sistema, de forma a este ser mais responsivo às necessidades da academia, bem como assegurar que a investigação se desenvolvesse como um bem público. Os princípios e as estratégias suportadas pela ACRL estavam conformes às linhas programáticas defendidas pelas declarações citadas anteriormente

No final de 2003, a IFLA publicou uma declaração sobre o acesso aberto à literatura científica e à documentação da investigação (IFLA Statement on Open Access to Scholarly Literature and Research Documentation, 05-12-2003). Identificava o papel da rede mundial de bibliotecas no acesso ao passado, presente e futuro da literatura científica e afirmava que o AA era essencial para a compreensão do mundo, e para a identificação de soluções para os desafios globais, particularmente a redução da desigualdade informacional, ou seja, "a constituição deste espaço público de partilha de informação" (Borges, 2006, p. 72). Reconhecia, também, que as bibliotecas eram parte integrante do conjunto dos atores envolvidos no arquivo e disseminação da investigação e, por isso, deveriam pugnar pelos sete princípios do AA enunciados no documento.

Estes princípios visavam assegurar a maior disponibilidade possível da literatura: (1) defesa dos direitos morais dos autores; (2) adoção de processos de revisão por pares, que assegurem a qualidade das publicações; (3) oposição à censura de publicações resultantes da investigação científica; (4) passagem a domínio público das publicações após o término do prazo de copyright, mas garantindo, de forma razoável, o acesso durante esse período; (5) implementação de medidas que evitem a desigualdade no acesso à informação; (6) apoio ao desenvolvimento de modelos e infraestruturas de publicação em acesso aberto, e (7) implementação de mecanismos, que garantam a preservação, acesso perpétuo, usabilidade e autenticidade de toda a documentação.

Com a análise deste percurso seminal, percebe-se que a questão do AA resulta simultaneamente de um problema do sistema de comunicação, dos investigadores, das bibliotecas e de todas as partes envolvidas, mas sobretudo de um problema comunitário:

O problema, no que se refere ao acesso à informação paga (toll-acess-licensing), é este: sempre que as bibliotecas não conseguem adquirir, e assim fornecer, o artigo científico original, existe um obstáculo real à investigação (e naturalmente ao impacto que um autor científico procura atingir). As bibliotecas, um mediador que pode ser indispensável no processo, podem suportar e encorajar o sistema de $\mathrm{OA}$ ou de auto-arquivo sempre que o primeiro não esteja disponível, mas só a comunidade de autores pode ser a grande responsável pela implementação do sistema (Borges, 2006, p. 75).

\section{A emergência da Cî̂nCia Aberta}

Se a solução passava pela comunidade de cientistas, sendo os cientistas os produtores da ciência, que oferecem gratuitamente os resultados da investigação, seria necessária então uma transformação da própria forma de fazer ciência? Estabelece-se então uma relação entre o AA e a CA, em que o primeiro se assume 
como um dos componentes da segunda:

\begin{abstract}
Quando se aborda o tema do open access, ao contrário do que se poderia esperar, tal não significa que se esteja perante um novo modo de fazer ciência, isto é, a forma atual de produzir ciência mantém-se inalterada, não se visualizando um novo paradigma científico, mas assistindo-se antes a novas práticas de investigação que, no caso do open access, são consubstanciadas na forma livre como as publicações científicas e técnicas são partilhadas e disponibilizadas na Internet, entre cientistas. (...) Assiste-se atualmente e crescentemente, entre a comunidade científica, a um movimento social mais alargado de abertura da ciência, que se concretiza não apenas na acessibilidade às publicações científicas resultantes das investigações, mas também numa maior visibilidade e transparência nas metodologias desenvolvidas pelos investigadores no decurso das suas pesquisas, nas estratégias e ferramentas de observação e de recolha de informação empírica, bem como na divulgação e disseminação dos dados recolhidos em si (Cardoso, Jacobetty e Duarte, 2012, pp. 5,18-19).
\end{abstract}

Sendo o AA um problema da comunidade de investigadores, mas no qual as bibliotecas estavam implicadas desde as origens, é importante sublinhar um dos aspetos evidenciados pelo estudo realizado no Reino Unido sobre o comportamento dos investigadores perante as bibliotecas das instituições do Ensino Superior (Research Information Network e Consortium of Research Libraries, 2007), isto é, as diferenças de perceção sobre o AA existentes entre bibliotecários e investigadores. Quase $50 \%$ dos investigadores responderam que a sua biblioteca nada fez para promover o AA. Apenas $4 \%$ dos investigadores indicaram que o bibliotecário os aconselhou a colocar os seus trabalhos em um repositório institucional e apenas $1 \%$ referiram que o bibliotecário os aconselhou a publicar em uma revista de acesso aberto (Geresteyn, 2014). Um dos elementos essenciais da expansão do movimento do AA foram os repositórios institucionais, criados e geridos na maior parte das instituições pelas bibliotecas. Não obstante a sua importância, em 2007 permaneciam ainda na sombra (Geresteyn, 2014).

Mas as propostas de transformação da ciência estavam em curso. Não cabe aqui enunciar exaustivamente as origens históricas da CA (ver por ex. David, 2008), mas enquanto cultura científica, que se formou em grande parte pelo impulso do movimento do AA, foi sendo cada vez mais reconhecida pelos media e pela sociedade a crescente necessidade de uma abertura da ciência. Este movimento de abertura conheceu um processo de aceleração com o desenvolvimento das redes digitais e, por isso, pode afirmar-se que a ciência ficou ainda "mais" aberta (Bartling e Friesike, 2014).

Entre as várias definições possíveis para CA encontra-se uma perspetiva tripla, entre dados de investigação, acesso às publicações e comunicação (The Royal Society, 2012). Mas se a comunicação é, de facto, a essência da ciência (Garvey, 1979), o que está em causa é a transformação da produção e disseminação da ciência mediante a utilização das potencialidades das tecnologias digitais, particularmente da computação hardware e software - e das redes que interligam os vários agentes envolvidos no ciclo da informação científica.

Como refere Caraça:

A ciência tornou-se verdadeiramente um saber fundacional das sociedades modernas nos últimos séculos porque, na sua cultura, a publicação dos resultados e das perceções dos cientistas constitui um valor essencial. A ciência vive porque se dá a conhecer. É este caráter público, de estar aberta, quer a quem publique quer a quem queira aceder a ela, que caracteriza insofismavelmente a cultura da ciência (Cardoso et al., 2012, pp. 14-15).

Um dos projetos financiados pela Comissão Europeia mais ativos nos últimos anos na área da CA, particularmente na formação dos investigadores, tem sido o FOSTER - Facilitate Open Science Training for European Research (iniciado em 2014) e o FOSTERPlus (iniciado em 2017), que se lhe seguiu. No âmbito dos conteúdos formativos elaborados no projeto encontra-se uma taxonomia da CA, que mostra a quantidade de áreas de trabalho e os termos que a constituem hoje (Cf. Pontika, Knoth, Cancellieri e Pearce, 2015). Neste contexto, já não estão em causa mudanças apenas no acesso aberto e nos dados abertos, mas a dinâmica de abertura estende-se à reprodutibilidade da ciência, à avaliação, às políticas e às infraestruturas, como é o caso dos repositórios de publicações científicas. 
Os contributos de autores como Pierre Bourdieu e Bruno Latour, que entenderam o campo científico como um território com regras próprias, mas não isolado do seu contexto social, político ou económico, e que perspetivaram a produção do conhecimento científico como permeável aos diferentes recursos externos convocados para a "vida do laboratório" - sejam atores, interesses, objetivos ou parcerias - exigem hoje a problematização da cultura da CA como um processo de transformação da própria ciência.

Neste processo estão em confronto dois fenómenos distintos. De um lado, "o desenvolvimento das formas de apropriação social da informação e do conhecimento (como bens públicos ou do comum); e, de outro, formas de apropriação privada desses intangíveis (como mercadorias)" (Jorge e Albagli, 2017, p. 219). De um lado, a colaboração e o desenvolvimento permitido pelas tecnologias digitais, e, do outro, a defesa intransigente da propriedade intelectual e a mercantilização do conhecimento. Em outro trabalho, Albagli (2015) defende que a CA faz parte de um quadro de tensão entre, por um lado, as novas formas de produção de informação, de conhecimento e de cultura, colaborativas, interativas e partilhadas, e, por outro, os mecanismos de captura e de privatização desse conhecimento que é produzido coletivamente e socialmente.

Por essa razão, a CA é um terreno de disputa entre várias perspetivas, em que a questão principal não reside apenas na integração das tecnologias digitais na produção e disseminação da ciência:

[os] discursos e iniciativas da ciência aberta sobre o papel da produção colaborativa também se dividem entre os que veem na maior colaboração a possibilidade de ampliar a participação e os benefícios sociais da ciência, e os que acreditam ser esta a melhor estratégia para ampliar a competitividade e o aumento das inovações (Jorge e Albagli, 2017, pp. 219-220).

Neste terreno de disputa confrontam-se diferentes escolas de pensamento, apresentadas por Fecher e Friesike (2014), tendo como referência o discurso da literatura sobre a CA: a escola de infraestrutura (que se preocupa com a arquitetura tecnológica), a escola pública (que se preocupa com a acessibilidade da criação de conhecimento), a escola de medição (que se preocupa com a medição alternativa do impacto), a escola democrática (que se preocupa com o acesso ao conhecimento) e a escola pragmática (que se preocupa com a ciência colaborativa).

O processo de abertura da ciência é uma dinâmica social e cultural que visa precisamente quebrar as fronteiras da ciência. Alguns autores propõem que a CA pretende a transformação dos paradigmas através de uma forte mobilização dos cientistas, pondo em causa o próprio sistema vigente:

a Ciência Aberta não procura a redefinição dos paradigmas científicos, mas antes a transformação dos paradigmas de investigaçãa. (...) Enquanto mobilização académica, a Ciência Aberta assume-se como reação à crescente privatização do conhecimento científico, derivada do estreitamento de relações entre ciência e mercados (Cardoso et al., 2012, p. 108).

No enunciado desta discursividade cabem ideias como a transparência dos métodos e dos resultados, a reutilização dos dados, a colaboração entre cientistas ou a ciência feita pelos cidadãos: "Ciência aberta não significa então apenas o acesso aberto a conhecimento. É um movimento que envolve um processo de atualização das práticas científicas frente às transformações tecnológicas, que auxiliam na formação de redes de conhecimento e potencializam sua produção coletiva” (Jorge e Albagli, 2017, p. 220).

\section{O PAPEL DAS BIBLIOTECAS NA ABERTURA DA CIÊNCIA}

No desenrolar deste percurso de abertura da ciência, qual é o lugar das bibliotecas neste novo discurso e nesta nova paisagem? Se forem consideradas parte integrante do sistema social da ciência, de que forma a CA também implica uma transformação das bibliotecas? De que forma as bibliotecas também colaboram na transformação da ciência? Estas perguntas não têm uma resposta imediata, mas dadas as pressões sociais, políticas e económicas que envolvem a CA é urgente que a reflexão sobre as bibliotecas também inclua estas questões como problemas de investigação. 
A LIBER (Ligue des Bibliothèques Européennes de Recherche - Association of European Research Libraries) elaborou um roteiro em que são indicadas as ações específicas que as bibliotecas podem desempenhar para o desenvolvimento da CA. As bibliotecas participam em todo o processo de investigação científica e estão, por isso, bem posicionadas para fazer a revolução acontecer através da advocacia da CA, do desenvolvimento de produtos e serviços, e do aumento do impacto através da colaboração e do estabelecimento de parcerias (LIBER, 2018). Neste roteiro, são apresentados os três princípios da CA na sua relação com as bibliotecas: transparência, sustentabilidade e colaboração.

Como é possível perceber nas definições de AA ou de CA, por elas perpassa uma onda tecnológica de transformações, sobejamente estudada, mas que é obrigatório referir. $\mathrm{O}$ impacto das tecnologias digitais no ensino superior e na investigação é um processo inegável (Borgman, 2007). A Internet, as redes, o desenvolvimento da computação, e todos os modos da "revolução" digital modificaram indelevelmente as formas e as práticas académicas (Weller, 2011).

Com diferentes níveis de resistência e de absorção, as práticas digitais possibilitaram a emergência da $e$ ciência, das humanidades digitais e da digitalscholarship (Mackenzie e Martin, 2016). Contudo, as práticas de investigação, antes de serem digitais ou abertas, são práticas de investigação. Os investigadores, antes de serem favoráveis a um uso intensivo das tecnologias digitais ou ativistas do AA, são investigadores (Esposito, 2013). Da mesma forma, as bibliotecas continuam a ser bibliotecas, apesar de terem experimentado uma rutura da sua conceção como repositórios físicos, em virtude do desenvolvimento da computação e das redes. Apesar de as bibliotecas manterem a sua missão, a sua natureza e aquilo que fazem estão a mudar rapidamente. As bibliotecas de investigação têm uma janela de oportunidade pós-Internet para gerir o conhecimento, desde a sua conceção até à sua publicação e preservação, pois beneficiam das lições aprendidas nas últimas décadas (Kennedy, 2018).

$\mathrm{Na}$ proposta de Weller (2011), as práticas académicas só podem ser realmente transformadas quando ocorre a convergência de três fatores: (1) a digitalização dos conteúdos, ou seja, a desmaterialização dos elementos analógicos; (2) a formação das redes, para partilha de saberes e recursos, e (3) a abertura, ou seja, o acesso livre ao conhecimento produzido. Este último fator é aquele que transporta uma maior potencialidade disruptiva no que toca à mudança efetiva das práticas. Para aquele autor, o "acesso livre" implica a adoção por parte dos investigadores de um conjunto de valores e de ideias que visa beneficiar e transformar a academia e a sociedade. Aqui se entra no domínio da política porque este quadro ideológico vai reclamar não apenas o acesso, mas também a mudança dos elementos tradicionais relativos à propriedade intelectual ou à validação científica.

Este itinerário de transformação digital, ainda em curso, conheceu nas últimas décadas o nascimento de um amplo movimento internacional - o AA - que é resultado do impacto das tecnologias digitais, mas também uma reivindicação antiga de diversos atores do sistema científico. As redes permitiram o aumento da partilha, da cooperação e a aceleração da comunicação entre os cientistas, porém estes elementos positivos, em tese, vieram colocar a descoberto o problema do acesso à informação no panorama da ciência. Problema antigo, já enunciado em 1948, na célebre conferência da Royal Society (McNinch, 1949), mas que nos anos 90 do século XX com o recrudescimento da Internet se tornava aparentemente fácil de resolver, não fossem os bloqueios do foro comercial que afetam há décadas o campo da informação científica e o agravamento da chamada Serials Crisis. Esta crise foi provocada pelo aumento exponencial dos preços das publicações científicas e a consequente incapacidade das instituições, particularmente as bibliotecas, em adquiri-las, gerando uma crise no acesso à informação por parte dos investigadores (Borges, 2006).

Numa revisão da literatura sobre a digital scholarship, demonstrou-se que os académicos digitais, quando refletem sobre as suas práticas ou quando são investigados sobre a transformação digital que está a ocorrer, não fazem praticamente referência às bibliotecas, aos bibliotecários, às suas competências e ao apoio que estes profissionais lhes prestam (Martin, 2016). A literatura é parca no conhecimento direto do comportamento dos investigadores, particularmente o conhecimento produzido por bibliotecários. Pelo contrário, a literatura 
é mais abundante quando se trata de estudos acerca das infraestruturas, como é o caso dos repositórios de publicações.

Martin (2016) identificou quatro temas recorrentes na literatura acerca das respostas das bibliotecas das instituições de Ensino Superior às mudanças no comportamento dos investigadores em face da transformação digital em curso: (1) a emergência de digital scholarship centres; (2) a mudança de papéis e os novos papéis assumidos pelas bibliotecas, bem como o desfasamento entre as competências tradicionais dos bibliotecários e as novas competências exigidas; (3) a mudança de um modelo de prestação de serviços para um modelo de parceria e colaboração com os investigadores, e (4) os temas da estratégia e da liderança, num equilíbrio entre práticas sustentáveis e inovação.

A autora sublinhou ainda que, apesar da falta de estudos mais aprofundados sobre o impacto verificado nas instituições após as mudanças operadas pelas bibliotecas, é surpreendente que: (1) os académicos desconheçam as capacidades dos bibliotecários e os serviços disponíveis nas bibliotecas, dispensando o seu apoio; (2) surjam com cada vez mais destaque serviços alternativos às bibliotecas, e (3) os bibliotecários não consigam compreender as necessidades dos investigadores. Clay (2016) reforça que os investigadores precisam de apoio para navegar no "mar revolto" da comunicação científica, para gerir os seus dados de investigação e para criar e explorar conteúdos digitais. Se as bibliotecas não forem capazes de fornecer esse apoio, outros o farão.

Recorrendo ao quadro de referência de Boyer (1990) acerca das quatro áreas em que a atividade académica se subdivide -, o conhecimento é obtido através de investigação, síntese, aplicação e ensino, o que constitui uma visão mais larga da atividade académica habitualmente circunscrita à investigação científica. Martin propôs uma síntese, a partir da análise da literatura, entre o que se conhece sobre o comportamento dos investigadores e os seus fluxos de trabalho, e os domínios nos quais as bibliotecas estão a conseguir acrescentar valor (Martin, 2016). É significativo que uma das palavras mais repetidas nesta síntese seja Open. Por esse motivo, a CA representa uma nova abordagem do processo científico, com base no trabalho cooperativo e nas novas formas de difusão de conhecimentos através das tecnologias digitais e das novas ferramentas colaborativas (Bueno de la Fuente, 2016b). A CA resulta da aplicação do princípio de abertura (openness) a todo o ciclo de investigação, promovendo a partilha e a colaboração desde o início até ao fim do processo, o que implica, assim, uma mudança sistémica da forma como a ciência é construída (Open Science and Research Initiative, 2014). Esta dinâmica é possível pela emergência anterior da ciberciência: "o espaço onde académicos e investigadores usam um novo meio comunicacional, suportado pela tecnologia digital, para desenvolver as suas actividades" (Borges, 2006, p. 110).

É difícil afirmar que a ciência quer mudar quando muitas das resistências à mudança advêm dos próprios investigadores. Na verdade, quem investiga procura publicar os seus resultados, mas espera o reconhecimento dos seus pares e da sociedade. $\mathrm{O}$ que ganham os investigadores com algumas mudanças tecnológicas como, por exemplo, a adoção de sistemas CRIS (Current Research Information Systems), por contraponto ao sucesso das redes sociais de investigadores gratuitas, e de utilização intuitiva? Como garantir que o sistema de recompensas, ao não ser devidamente tido em conta, não impede o desenvolvimento e a mudança da organização da ciência?

Não obstante a existência destas questões pode afirmar-se com segurança que o poder político tem demonstrado, com um crescente grau de intensidade, a vontade de alterar diversos aspetos relacionados com a organização e a comunicação da ciência. A generalidade dos cientistas apoia e corrobora esta mudança, na medida em que vai compreendendo as vantagens que estão associadas a esta transformação.

Tem surgido assim um amplo movimento internacional (Santos, Almeida, e Henning, 2017) no qual a União Europeia tem tido um papel importante. $\mathrm{O}$ mais importante projeto financiado pela Comissão Europeia nesta área denomina-se OpenAIRE - Open Access Infrastructure for Research in Europe, que desde 2009 tem sido sucessivamente renovado, em OpenAIREplus (desde 2011) e em OpenAIRE2020 (desde 2015). O mais recente quadro de apoio comunitário, o Horizonte 2020, representa uma estratégia para 
uma economia inteligente, sustentável e inclusiva. Sublinha também o papel central do conhecimento e da inovação na geração de crescimento. $\mathrm{O}$ acesso alargado e completo às publicações e aos dados de investigação permitirá construir sobre os resultados prévios da investigação, promover a colaboração e evitar duplicações de esforços, acelerar a inovação, e envolver os cidadãos e a sociedade no processo de investigação científica (European Commission, 2017).

Qual é então, em suma, o papel das bibliotecas neste quadro novo da CA? Em primeiro lugar, é preciso ter em conta o papel desempenhado no passado relativamente ao acesso aberto às publicações e no acesso aos dados abertos. Esta experiência coloca as bibliotecas numa posição privilegiada para integrar esta nova cultura (Bueno de la Fuente, 2016a). Recorde-se que o problema fundamental é o debate em curso acerca dos novos papéis das bibliotecas na era digital. Desta forma, a relação das bibliotecas com a CA tem de ser lida como um filão de uma problemática mais vasta, da qual a Ciência da Informação se tem ocupado nas últimas décadas.

No quadro da União Europeia e das suas preocupações relativamente à preservação dos resultados da investigação científica, as bibliotecas aparecem associadas a uma dimensão tradicional, ficando em aberto o seu papel no acesso e preservação da informação científica. Refira-se, aliás, que as palavras biblioteca e bibliotecas apenas surgem no seguinte trecho, replicado em duas das mais importantes recomendações da Comissão Europeia sobre o acesso à informação científica e a sua preservação:

A preservação dos resultados da investigação científica é do interesse público. Tradicionalmente, tem sido responsabilidade das bibliotecas ou dos arquivos, especialmente das bibliotecas nacionais encarregadas do depósito legal. O volume de resultados de investigação produzidos está a aumentar constantemente. Devem ser criados mecanismos, infraestruturas e soluções de software que permitam preservar a longo prazo, em formato digital, os resultados da investigação (Comissão Europeia, 2018, p. 13, ver também 2012, p. 40).

Para a OCDE, as bibliotecas são atores-chave na CA, na medida em que a operacionalizam (2015) - em conjunto com outros stakeholders como os investigadores, as agências de financiamento, as universidades, os editores, entre outros. Como elementos centrais de uma "cultura de dados abertos", as bibliotecas são, sobretudo, facilitadoras da CA; são a infraestrutura física que permite aos cientistas partilhar, usar e reutilizar o conhecimento. Graças às tecnologias digitais, as bibliotecas assumiram um novo papel e estão ativas na preservação, curadoria, publicação e disseminação de recursos científicos, na forma de publicações, dados e outros conteúdos relacionados com a investigação (OCDE, 2015).

As instituições de acolhimento da investigação deveriam entender as bibliotecas como fazendo parte da categoria de medidas e políticas a implementar juntamente com o que Bueno de la Fuente chama de paus (ex. regras, políticas, estratégias) e de cenouras (ex. incentivos financeiros). Daí que, segundo esta autora, as bibliotecas possam desempenhar quatro papéis distintos na CA: advocacy e conscientização, apoio a infraestruturas como os repositórios, gestão de dados de investigação (Research Data Management), formação e apoio dos investigadores ao longo do ciclo de vida da investigação incluindo os complexos processos de avaliação da ciência. Estes papéis exigem que as bibliotecas conheçam bem as práticas das comunidades, e que os profissionais de informação desenvolvam um conjunto de competências específicas (Bueno de la Fuente, 2016a).

\section{ConClusão}

Para as bibliotecas que se relacionam com os investigadores, esta dinâmica de abertura da ciência é mais uma oportunidade para a transformação do ciclo da investigação e do seu lugar nesse ciclo. Mas esta transformação tem de ser efetiva e não apenas passageira, evitando-se a aplicação de esquemas de pensamento desadequados aos atuais panoramas da ciência.

Em suma, o AA terá emergido de uma crise do sistema de comunicação da ciência, que afetava fortemente as bibliotecas, e, nesse sentido, as bibliotecas participaram nas origens do movimento e aproveitaram toda 
a dinâmica instaurada para se tentarem posicionar como um dos atores relevantes na chamada reforma do sistema. Daí que hoje seja evidente que as bibliotecas são um dos atores mais relevantes na dinâmica da CA, procurando de uma forma proeminente intervir em todo o ciclo da investigação científica.

Desta forma, a análise do papel das bibliotecas na investigação científica não pode deixar de ter em conta este panorama. Os investigadores encaram o papel das bibliotecas neste amplo e novo panorama científico com algum distanciamento, mas não deixam - como a literatura revela - de reconhecer a relevância dos novos serviços que estas desenvolvem para apoiá-los.

Conclui-se que as bibliotecas participaram desde o início no processo de abertura da ciência e continuam hoje a pugnar pelo desempenho de um papel relevante neste processo social e cultural.

\section{REFERÊNCIAS}

Albagli, S. (2015). Open science in question. Em S. Albagli, M. L. Maciel, e A. H. Abdo (Eds.), Open Science, open issues (pp. 9-25). Brasília: IBICT. Obtido de http://livroaberto.ibict.br/handle/1/1061

Bartling, S., e Friesike, S. (Eds.). (2014). Opening Science: The Evolving Guide on How the Internet is Changing Research, Collaboration and Scholarly Publishing. Cham: Springer. https://doi.org/10.1007/978-3-319-00026-8

Bethesda Statement on Open Access Publishing (2003). Obtido de https://legacy.earlham.edu/ peters/fos/bethesda.h tm

Budapest Open Access Initiative [BOAI] (2002). Declaration after the Open Society Institute meeting in Budapest December 1-2 2001. Budapest: Open Society Institute. Obtido de http://www.soros.org/openaccess/read.shtml

Budapest Open Access Initiative [BOAI] (2017). Dez anos depois da Budapest Open Access Initiative: estabelecendo o Acesso Aberto como padrão. Obtido de https://www.budapestopenaccessinitiative.org/boai-10-translations/por tuguese

Borges, M. M. (2006). A esfera: Comunicação académica e novos media (Tese de doutoramento). Universidade de Coimbra, Coimbra. Obtido de http://hdl.handle.net/10316/8557

Borgman, C. L. (2007). Scholarship in the digital age: information, infrastructure, and the Internet. Cambridge, Massachusetts: The MIT Press.

Borgman, C. L. (2015). Big data, little data, no data: scholarship in the networked world. Cambridge, Massachusetts: The MIT Press.

Boyer, E. L. (1990). Scholarship reconsidered: priorities of the professoriate. Stanford, CA: The Carnegie Foundation for the Advancement of Teaching.

Bueno de la Fuente, G. (2016a). Libraries: roles and opportunities on Open Science. Obtido de https://www.fosterop enscience.eu/node/1426

Bueno de la Fuente, G. (2016b). What is Open Science? Introduction. Obtido de https://www.fosteropenscience.eu/ node/ 1420

Cardoso, G., Jacobetty, P., e Duarte, A. (2012). Para Uma Ciência Aberta. Lisboa: Mundos Sociais.

Clay, D. (2016). Building scalable and sustainable services for researchers. Em A. Mackenzie e L. Martin (Eds.), Developing digital scholarship: emerging practices in academic libraries (pp. 121-138). London: Facet publishing.

Comissão Europeia (2012). Recomendação da Comissão de 17 de julho de 2012 sobre o acesso à informação científica e a sua preservação (2012/417/UE). Jornal Oficial da União Europeia, L194, 39-43. Obtido de https://eur-lex. europa.eu/legal-content/PT/TXT/PDF/?uri=CELEX:32012H0417\&from=PT

Comissão Europeia. (2018). Recomendação (UE) 2018/790 da Comissão de 25 de abril de 2018 sobre o acesso à informação científica e a sua preservação. Jornal Oficial da União Europeia, L134, 12-18. Obtido de https://eur -lex.europa.eu/legal-content/PT/TXT/PDF/?uri=CELEX:32018H0790\&from=EN

David, P. A. (2008). The Historical Origins of «Open Science»: An Essay on Patronage, Reputation and Common Agency Contracting in the Scientific Revolution. Capitalism and Society, 3(2). https://doi.org/10.2202/1932 $-0213.1040$ 
Esposito, A. (2013). Neither digital or open. Just researchers. Views on digital/open scholarship practices in an Italian university. First Monday, 18(1). Obtido de https://journals.uic.edu/ojs/index.php/fm/article/view/3881/3404

European Commission. (2017). Guidelines to the rules on Open Access to Scientific Publication and Open Access to Research Data in Horizon 2020 - version 3.2. European Commission. Obtido de http://ec.europa.eu/research/ participants/data/ref/h2020/grants_manual/hi/oa_pilot/h2020-hi-oa-pilot-guide_en.pdf

Fecher, B. e Friesike, S. (2014). Open Science: One Term, Five Schools of Thought. Em S. Bartling e S. Friesike (Eds.), Opening Science: The Evolving Guide on How the Internet is Changing Research, Collaboration and Scholarly Publishing (pp. 17-48). Cham: Springer. Obtido de https://link.springer.com/book/10.1007\%2F978-3-319-0 0026-8

Friend, F. J. (2006). Towards open access to UK research. Em N. Jacobs (Ed.), Open Access: Key Strategic, Technical and Economic Aspects (pp. 161-167). Oxford: Chandos.

Garvey, W. D. (1979). Communication: the essence of science: facilitating information exchange among librarians, scientists, engineers and students. Oxford: Pergamon Press.

Geresteyn, D. van. (2014). What scholars think about open access: An overview of the developments in scholars' awareness and attitude towards open access publishing between 1992 and 2014 (Dissertação de mestrado). Leiden University, Leiden. Obtido de https://openaccess.leidenuniv.nl/handle/1887/29761

IFLA (2003). IFLA Statement on Open Access to Scholarly Literature and Research Documentation. Obtido de https:// www.ifla.org/publications/ifla-statement-on-open-access-to-scholarly-literature-and-research-documentation

Jorge, V. e Albagli, S. (2017). Pierre Bourdieu e a produção do conhecimento científico: reflexões sobre uma ciência aberta. Em R. M. Marteleto e R. M. Pimenta (Eds.), Pierre Bourdieu e a produção social da cultura, do conhecimento e da informação (pp. 207-228). Rio de Janeiro: Garamond.

Kennedy, M. L. (2018). The Opportunity for Research Libraries in 2018 and Beyond [Post-Print]. Portal: Libraries and the Academy, 18(4), 629-637.

LIBER (2018). LIBER Open Science Roadmap. Em F. Grant (Ed.). [S.I.]: LIBER. https://doi.org/10.5281/zenodo.1 303002

Mackenzie, A. e Martin, L. (Eds.) (2016). Developing digital scholarship: emerging practices in academic libraries. London: Facet publishing.

Martin, L. (2016). The university library and digital scholarship: a review of the literature. Em A. Mackenzie e L. Martin (Eds.), Developing digital scholarship: emerging practices in academic libraries (pp. 3-22). London: Facet publishing.

McNinch, J. H. (1949). The Royal Society Scientific Information Conference, London, June 21-July 2, 1948. Bulletin of the Medical Library Association, 37(2), 136-141. Obtido de http://www.ncbi.nlm.nih.gov/pmc/articles/PM C194801/

Moore, S. A. (2017). A genealogy of open access: negotiations between openness and access to research. Revue française des sciences de l'information et de la communication, 11, 1-16. Obtido de http://rfsic.revues.org/3220

OCDE (2015). Making Open Science a Reality. Paris: OECD Publishing. Obtido de http://dx.doi.org/10.1787/5jrs 2f963zs1-en

Open Science and Research Initiative (2014). Open Science and Research Handbook. Obtido de https://avointiede.fi/documents/14273/0/Open+Science+and+Research+Handbook+v.1.0/50316d5d-4 40b-4496-b039-2997663afff8

Pontika, N., Knoth, P., Cancellieri, M., e Pearce, S. (2015). Fostering Open Science to Research using a Taxonomy and an eLearning Portal. Em iKnow: 15th International Conference on Knowledge Technologies and Data Driven Business. Graz, Austria. https://doi.org/10.1145/2809563.2809571

Research Information Network e Consortium of Research Libraries (2007). Researchers' use of academic libraries and theirservices. Obtido de http://www.rin.ac.uk/system/files/attachments/Researchers-libraries-services-report.p df 
Santos, P. X. dos, Almeida, B. de A., e Henning, P. (Eds.). (2017). Livro Verde - Ciência aberta e dados abertos: mapeamento e análise de politicas, infraestruturas e estratégias em perspectiva nacional e internacional. Rio de Janeiro: Fiocruz.

Suber, P. (2004). Praising progress, preserving precision. SPARC Open Access Newsletter, 77. Obtido de https://dash. harvard.edu/bitstream/handle/1/4736612/suber_praising.htm?sequence $=1$

Suber, P. (2012). Open access. Cambridge, Massachusetts: The MIT Press.

The Royal Society. (2012). Science as an open enterprise. London: The Royal Society. Obtido de https://royalsociety.o $\mathrm{rg} / \sim /$ media/policy/projects/sape/2012-06-20-saoe.pdf

Weller, M. (2011). The Digital Scholar: How Technology Is Transforming Scholarly Practice. London: Bloomsbury Academic. 